\title{
Power Quality Improvement of an Isolated Wind Power Generation System
}

\author{
Bhavna Jain ${ }^{1}$, Taruna Jain ${ }^{2}$, Shailendra Jain ${ }^{3}$, and R. K. Nema ${ }^{3}$ \\ ${ }^{I}$ (Associate Professor, Department of Electrical and Electronics Engineering, RITS, Bhopal, India) \\ ${ }_{2}^{2}$ (Associate Professor, Department of Electrical Engineering, BUIT, Bhopal, India) \\ ${ }^{3}$ (Professor, Department of Electrical Engineering, MANIT, Bhopal, India)
}

\begin{abstract}
Most of the renewable energy generation systems, such as wind power generation system do not have constant power generation pattern due to their dependence on climate conditions. Therefore, it becomes impractical to install them as an isolated system without an optional power generation unit or battery backup for getting consistent output power. In remote areas, the grid electrification may not always be feasible. Above factors have led to conceptualization of isolated wind power generation system (IWPGS) working under varying wind and load conditions. However, the harmonics generated due to the power electronic interface, non-linear loads connected to the system and reactive power consumption by all such loads, leads to power quality deterioration. This paper deals with one such solution to the power quality problems associated with IWPGS in form of active power filter (APF) and its performance is demonstrated through comparison on various indices.

Keywords- Active power filter (APF), Battery energy storage unit (BESU), isolated wind power generation system (IWPGS), permanent magnet synchronous generator (PMSG), total harmonic distortion(THD)
\end{abstract}

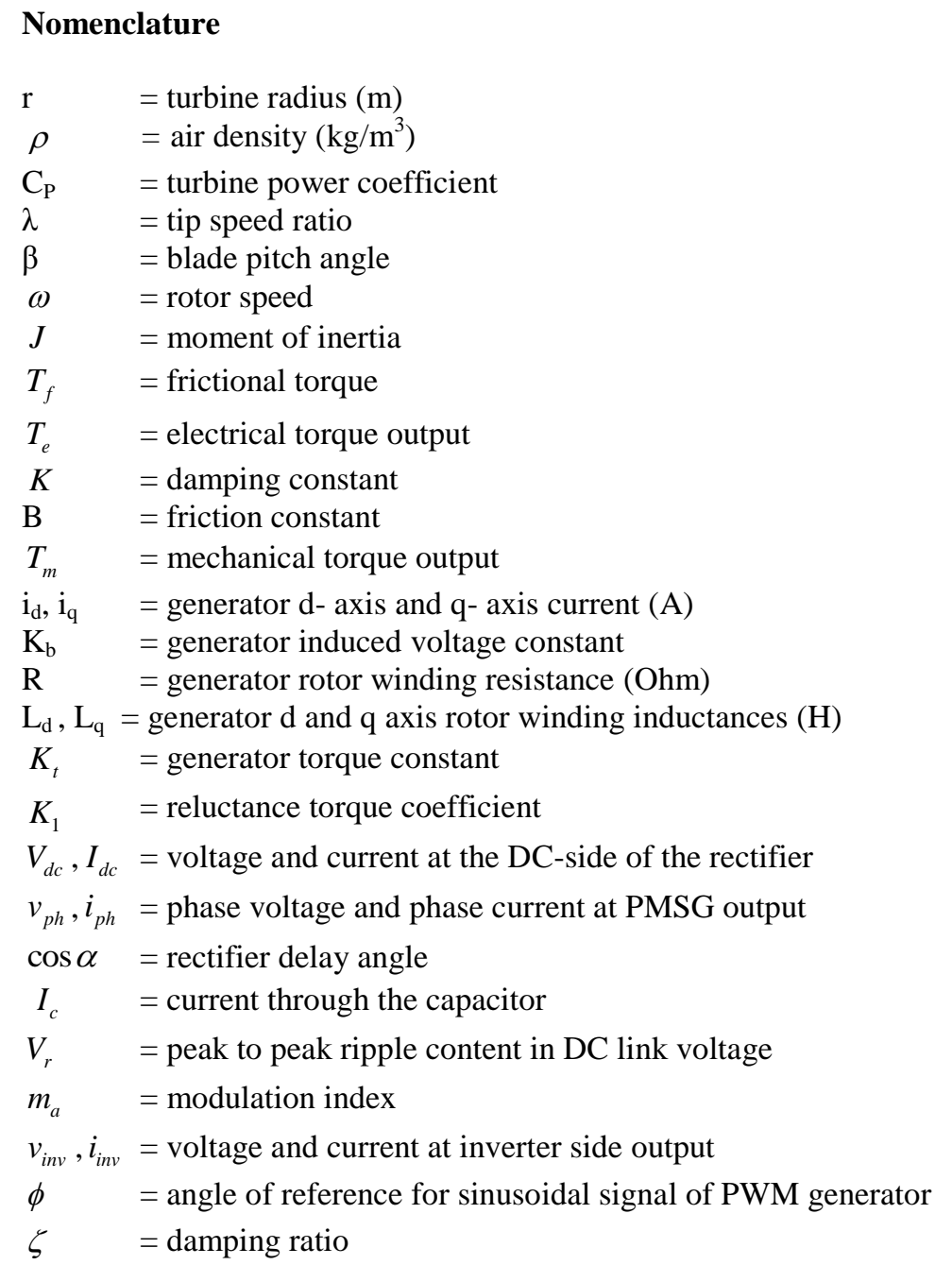




$$
\begin{array}{lr}
\omega_{n} & =\text { natural frequency }(\mathrm{Hz}) \\
T_{s} & =\text { sampling time }
\end{array}
$$

\section{Introduction}

Isolated renewable energy systems are finding wide application with increasing incursion of power supply to rural electrification [1]. The isolated system using renewable energy sources like wind, solar with battery backup or fuel cell may prove to be preferable over grid electrification, when criteria like cost and distance are predominant. Ratings of these isolated systems may range from a few kilowatt-hours to many megawatt-hours per day [2]. In isolated systems using wind energy, electrical generator generates power at variable voltage and frequency due to continuous change in wind speed [3]. This power is converted into DC by the rectifier of power electronic interface [4-7]. At the DC link of interface, this power is either converted into AC power at rated voltage and frequency through inverter, to be fed to the load or is stored in the battery, as per load conditions. The battery backup arrangement reduces fluctuations in power and allows supplying power to load at later instants $[8,9]$.

New generation of utilities mostly use power electronic devices as an integral part, due to which power quality of the system no longer remains sinusoidal. In integrated system as well as in isolated wind power generation system (IWPGS), the critical condition is to observe the impact of load power variation on the power quality of system [10-12]. In isolated system, load also shows impact on system voltage and power factor, like during light load conditions the voltage may become high and power factor leading. Although sufficient literature is available in WPGS employing power electronic interface for voltage and frequency control. But the power quality problems are not addressed completely. Poor power quality of the system may be reflected in form of low efficiency, poor voltage regulation, harmonic generation and poor power factor. Thus, power quality improvement is required for the system to comply with the IEC 61400 or IEEE 519 standards [13].

In this paper, a simplified model of a scaled down IWPGS is developed and effects of variations in wind and load are observed. Reliability of the system is assured by introducing battery energy storage unit. Further, active power filter (APF) is inserted to improve the power quality of IWPGS in terms of harmonic and reactive power compensation [14, 15]. The performance of IWPGS is observed in steady state and during transients with and without filter; the improvement in performance is discussed through comparative analysis on factors influencing power quality like \% THD in voltage and current, power factor and reactive power consumption.

\section{Modeling Of Isolated Wind Power Generation System}

A simulation model of IWPGS for remote application is developed by investigating an optimized daily load requirement and operating conditions for a typical household power consuming load as given in Table I. The peak load is calculated by summing up the rated power of all the appliances expected to be connected. However, transient currents are calculated by using start up characteristics of non-linear or linear loads. Nonlinear loads commonly used by consumers (electronic appliances) include diode rectifier with reactive element on DC side. Linear loads include dynamic loads like single phase induction motors and resistive and inductive loads. Most real loads, for example refrigerator, incandescent and fluorescent lights, computers, water pump and other electronic appliances show non-linear characteristic.

The IWPGS model is constituted by a variable wind speed, variable pitch wind turbine, aerodynamic converter, a permanent magnet synchronous generator and a power electronic interface as shown in Fig. 1 [1618]. While developing the model of IWPGS, the point taken care for is, the developed model should be such that, it can be easily integrated to multiple loads for dynamic analysis.

For the above purpose, the IWPGS is divided into various subsystems as shown in Fig. 2, namely-

1. Mechanical subsystem

- Wind speed

- Wind turbine

- Aerodynamic converter

2. Electrical subsystem

- Electric generator

- Power electronic interface 


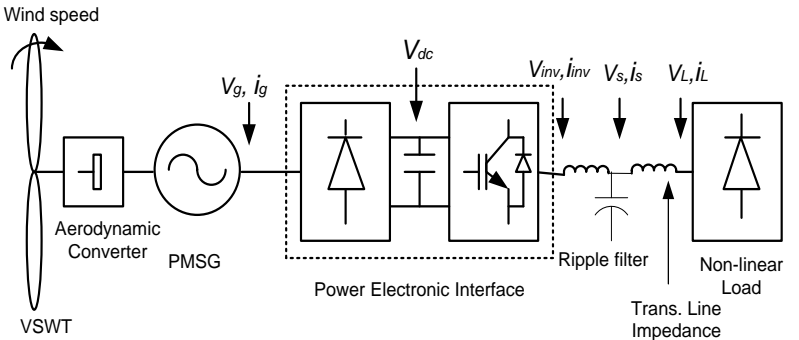

Fig.1 Schematic diagram of IWPGS

Table - I

TYPICAL HOUSEHOLD DAILY POWER REQUIREMENT

\begin{tabular}{llllll}
\hline S.No. & Load type & Quantity & $\begin{array}{l}\text { Consumption } \\
\text { (Watt) }\end{array}$ & $\begin{array}{l}\text { Hours of use } \\
\text { (per day) }\end{array}$ & $\begin{array}{l}\text { Energy } \\
\text { consumption(kWhr) }\end{array}$ \\
\hline 1. & CFL/Fluorescent lamp & 10 & $30 \times 10=300$ & $6 \times 10=60$ & 18.00 \\
2. & Fan & 6 & $50 \times 6=300$ & $12 \times 6=72$ & 21.60 \\
3. & Refrigerator & 1 & $100 \times 1=100$ & $24 \times 1=24$ & 2.40 \\
4. & TV/ DVD & $1+1$ & $150 \times 2=300$ & $4 \times 2=8$ & 2.40 \\
5. & Computer/ & $1+1+1$ & $250 \times 3=750$ & $2 \times 3=6$ & 4.50 \\
& printer/laptop & 2 & & & 72.00 \\
6. & AC $(1.5$ ton) & 1 & $2250 \times 2=4500$ & $8 \times 2=16$ & 1.00 \\
7. & Microwave oven & 1 & $1000 \times 1=1000$ & $1 \times 1=1$ & 1.25 \\
8. & Geyser & 1 & $1250 \times 1=1250$ & $1 \times 1=1$ & 1.50 \\
9. & Water pump & & $1500 \times 1=1500$ & $1 \times 1=1$ & Total energy \\
\hline Peak load & & 10000 & consumption & 124.65 \\
\end{tabular}

\section{A. Modeling of Mechanical Subsystem}

IWPGS is different from conventional power generation systems in the way that the prime mover here is variable wind. Mechanical subsystem is modeled as cascaded blocks of wind speed model, wind turbine and aerodynamic converter. Mechanical subsystem receives variable wind speed as input to wind speed model, converts kinetic energy of wind into mechanical torque in wind turbine, providing mechanical power and rotational speed as output quantities at aerodynamic converter output.

\section{Wind Speed}

Wind speed has random behavior; it varies continuously in an uncontrolled manner as a function of time and height above sea level, thereby resulting in variation in turbine output. Wind speed also varies depending upon the natural conditions like weather, temperature and the landscape. To model wind speed, the sources of wind speed and its variation due to each of them is to be considered separately. It is assumed that wind speed signal is accumulative effect of four components of wind; they are base wind speed $v_{b s}$, wind gust $v_{g}$, wind speed ramp $v_{r}$ and the turbulence occurring in the wind i.e. random wind speed $v_{n}$ [19].

Hence wind speed $v$ may be modeled as given by Eq. (1) -

$$
v=v_{b s}+v_{g}+v_{r}+v_{n}
$$

\section{Wind Turbine}

Wind turbine rotor converts wind energy input into mechanical power output, thus representing a complex aerodynamic system. The wind energy captured by wind turbine depends on the design features of turbine and the operating conditions. Variable speed wind turbine offers great operating flexibility and reduced mechanical stress over fixed speed wind turbine. The torque spike due the wind gust and the audible noise at light wind is reduced with variable speed wind turbines [20,21]. The rotor aerodynamics provides rated output power by regulating power at high wind speeds with pitch angle control. Pitch angle control is mechanical control applied to turbine blade, to maintain optimum power output with varying wind input. In the aerodynamic system, the equivalent wind speed input helps compute available mechanical power as shown in Fig. 2. Below rated wind speed, the initial input is decided by power output from the wind turbine using comparator, while above rated wind speed, wind speed itself becomes the deciding factor.

To obtain optimized mechanical power output from wind turbine, it becomes indispensable to control the factors influenced by wind speed variation, they are specified as tip speed ratio and power coefficient of wind turbine. The aerodynamic efficiency of wind turbine of a particular size is defined as the ratio of turbine power to wind power and known as power coefficient $C_{P}$ given by Eq. (2) [22]- 


$$
C_{P}=\frac{P}{P_{m}}
$$

When electrical behavior of the wind turbine is to be discussed for simplified system, mechanical power captured by wind turbine rotor may be described by the Betz's formula given by Eq. (3) -

(3)

$$
P_{m}=\frac{1}{2} \pi \rho C_{P} r^{2} v^{3}
$$

Here $\mathrm{Cp}$ turbine power coefficient is a function of tip speed ratio $\lambda$ and blade pitch angle $\beta$. Therefore, if the air density, swept area, and wind speed are constant, the output power of the wind turbine is a function of power coefficient of the turbine. Power coefficient $C_{P}$ is calculated with the help of empirical formula [18] as shown in Eq. (4) and (5) -

$$
C_{P}=0.5176\left[\frac{116}{\lambda_{1}}-0.4 \beta-5\right] \exp \left(-\frac{21}{\lambda_{1}}\right)+0.0068 \lambda
$$

Where

$$
\frac{1}{\lambda_{1}}=\left[\frac{1}{\lambda+0.08 \beta}-\frac{0.035}{\beta^{3}+1}\right]
$$

And tip-speed ratio (TSR) is given by Eq. (6) -

$$
\lambda=\frac{\omega_{m} r}{v}
$$

The dimensionless power coefficient $C_{P}$ represents the efficiency of wind turbine to transform the kinetic energy of moving air into mechanical torque at the turbine shaft at a specific tip speed ratio. In general, for variable speed wind turbine maximum power can be obtained up to the rated speed by tracking $\mathrm{C}_{\mathrm{P}}$ to its maximum value for optimum TSR, by changing rotor speed. However, only a fixed percentage of wind energy is converted into mechanical power and it is decided by turbine power coefficient $\mathrm{C}_{\mathrm{p}}$ known as Betz limit and $\mathrm{C}_{\mathrm{pmax}}=0.59$.

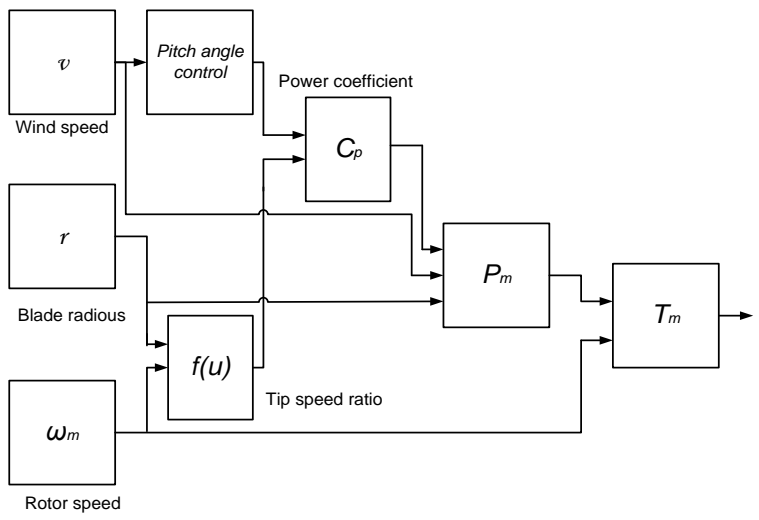

Fig.2 Schematic diagram of variable speed wind turbine with pitch angle control

\section{Aerodynamic Converter}

The mechanical quantities connecting wind turbine with electrical generator are mechanical torque and rotational speed of shaft. The aerodynamic converter provides rated output power by regulating mechanical torque at high wind speeds. Aerodynamic converter includes inertia of both turbine and generator as shown in Fig.3. The shaft connecting the wind turbine and electrical generator is modeled as a spring and a damper. A soft shaft is assumed for modeling and rotor aerodynamics can be implemented using Eq. (7) -

$$
\frac{d \omega}{d t}=\frac{1}{J}\left(T_{e}-T_{f}-T_{m}\right)=\frac{1}{J}\left(T_{e}-K \Delta \theta-B \Delta \omega-T_{m}\right)
$$

Here, $\Delta \theta=\theta_{m}-\theta_{e}, \Delta \omega=\omega_{m}-\omega_{e}, \theta=\int \omega$ and $\theta_{e}=\frac{p}{2} \theta_{m}$.

Aerodynamic torque is given by Eq. (8) - 
(8)

$$
T_{m}=\frac{1}{2} \pi \rho R^{3} C_{Q}(\lambda) v^{2}
$$

Where the torque coefficient $\mathrm{C}_{\mathrm{Q}}$ is calculated from Eq. (9) -

$$
C_{Q}(\lambda)=\frac{C_{P}(\lambda)}{\lambda}
$$

(9)

The rotor aerodynamic power is given by Eq. (10) -

$$
P_{m}=\omega_{m} T_{m}
$$

The generated power is given by Eq. (11) -

(11)

$$
P_{e}=\omega_{e} T_{e}
$$

The aerodynamic torque drives the wind turbine at the speed $\omega_{\mathrm{m}}$, at low speed this torque acts as braking torque and at high speed it runs the generator.

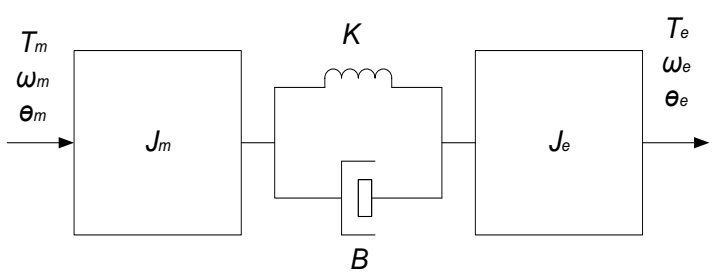

Fig.3 Schematic diagram of aerodynamic converter

\section{B. Modeling of Electrical Subsystem}

The electrical subsystem is modeled as permanent magnet synchronous generator (PMSG) having power electronic interface (PEI) giving sinusoidal three phase supply to load/grid. With the development in IWPGS; various types of electrical generators, as per ratings and types of application are proposed to increase power generation [23]. PMSG dominates other types of electrical generators for its superior characteristics like, operation at high power factor and efficiency due to self excitation and higher reliability due to absence of carbon brushes and slip rings, low level of acoustic noise due to elimination of gear box. However, due to synchronous operation the PMSG may suffer from instability under short circuit transient occurrences. Demagnetization of poles is also seen as uncontrolled factor along with reduced flexibility of operation [24].

\section{Permanent Magnet Synchronous Generator}

PMSG is popularly used with VSWT due to its quality of extracting optimum power at varying wind speed. To develop dynamic model as shown in Fig. 4, of the PMSG using synchronous reference frame, following assumptions are made [25]-

1. Spatial distribution of magnetic flux in the air gap is sinusoidal.

2. Magnetic circuit is linear.

The 3-phase sinusoidal voltages of PMSG are converted into equivalent d-q axis voltages by Park's transformation as given by Eq. (12), (13) and (14) -

$$
v_{d}=\frac{2}{3}\left[v_{a} \sin \omega t+v_{b} \sin \left(\omega t-\frac{2 \pi}{3}\right)+v_{c} \sin \left(\omega t+\frac{2 \pi}{3}\right)\right]
$$

$$
v_{q}=\frac{2}{3}\left[v_{a} \cos \omega t+v_{b} \cos \left(\omega t-\frac{2 \pi}{3}\right)+v_{c} \cos \left(\omega t+\frac{2 \pi}{3}\right)\right]
$$

$$
v_{0}=\frac{1}{3}\left[v_{a}+v_{b}+v_{c}\right]
$$

The d-q axis model of the PMSG is presented by Eq. (15) and (16) -

$$
\frac{d i_{d}}{d t}=-\frac{R}{L_{d}} i_{d}-\frac{\omega L_{q}}{L_{d}} i_{q}-\frac{1}{L_{d}} v_{d}
$$


(16)

$$
\frac{d i_{q}}{d t}=-\frac{R}{L_{q}} i_{q}+\frac{\omega L_{d}}{L_{q}} i_{d}-\frac{1}{L_{q}} v_{q}+\frac{K_{b}}{L_{q}} v
$$

These $i_{d}, i_{q}$ currents are converted back into phase currents $i_{a}, i_{b}, i_{c}$ using following Eq. (17), (18) and (19) -

$$
i_{a}=i_{q} \cos \omega t+i_{d} \sin \omega t
$$

$$
\begin{aligned}
& i_{b}=i_{q} \cos \left(\omega t-\frac{2 \pi}{3}\right)+i_{d} \sin \left(\omega t-\frac{2 \pi}{3}\right) \\
& i_{c}=i_{q} \cos \left(\omega t+\frac{2 \pi}{3}\right)+i_{d} \sin \left(\omega t+\frac{2 \pi}{3}\right)
\end{aligned}
$$

And electrical torque is given by Eq. (20)-

$$
T_{e}=K_{t} i_{q}+K_{1}\left(L_{d}-L_{q}\right) i_{d} i_{q}
$$

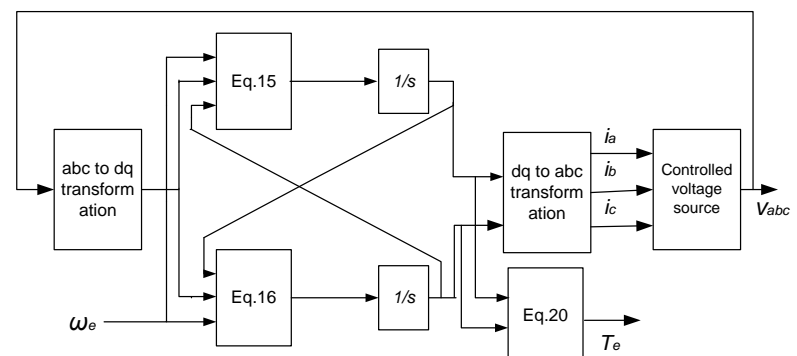

Fig.4 Schematic diagram of PMSG

Electrical power available at the PMSG output of the IWPGS is not sinusoidal in nature. To get the sinusoidal voltage at supply frequency and to keep the output power optimally constant, power electronic interfacing is done between generator and grid /load.

\section{Power Electronic Interface}

In general, PEI device is a combination of a rectifier, an energy storage device to regulate the DC link voltage and an inverter. Power electronic converters with higher rating and low power losses offer great control over a wide range of power ratings and are becoming more attractive as PEI device to improve the overall performance of variable speed IWPGS. DC link capacitor used at the intermittent stage decouples the two converters, offering separate control for both generator side and grid/load side parameters independently. However, in some papers, drawbacks associated with DC link capacitor are listed as, it is bulky and heavy, increases the cost of the system and it reduces overall lifetime of the system [7]. The rectifier-inverter interface (RII) shown in Fig. 5 is most commonly used combination opted for PEI in IWPGS for getting constant power and sinusoidal voltage at rated frequency. The voltage available at generator output is fed to the three phase rectifier, which converts it into the DC voltage; DC link capacitor on the DC side of rectifier regulates this voltage and feeds to the three phase MOSFET inverter. The 3-phase voltage available finally at the output of the inverter at rated frequency is supplied to the grid/load.

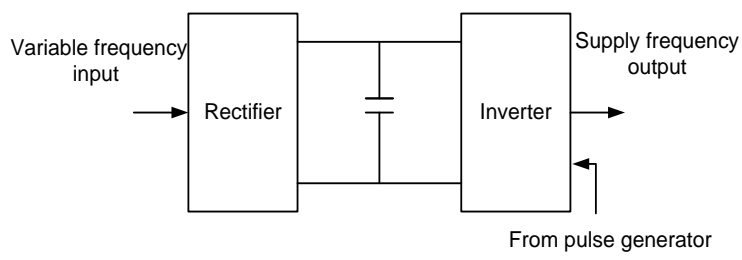

Fig.5 Schematic diagram of RII

Voltage and current available at the DC side of the rectifier may be represented by Eq. (21) and (22)- 


$$
V_{d c}=\frac{3 \sqrt{3}}{\pi} v_{p h} \cos \alpha
$$

$$
I_{d c}=\frac{\pi}{2 \sqrt{3 \cos \alpha}} i_{p h}
$$

DC link capacitor smoothens above voltage by absorbing ripples in it. The DC link voltage across the capacitor is chosen more than the peak supply voltage to keep track with the change in load demand [12, 21]. This voltage is the minimum voltage required to make system stable. However, at the same time low DC link voltage is desirable to reduce switching losses. Design of DC link capacitor may be done by considering maximum permissible current ripples and maximum ripple voltage allowable. Hence value of DC link capacitor $\mathrm{C}_{\mathrm{dc}}$ can be found from Eq. 23-

$$
C_{d c}=\frac{\pi * I_{c}}{\sqrt{3} \omega V_{r}}
$$

The inverter output Eq. (24) and (25) are given as-

$$
\begin{aligned}
& v_{i n v}=m_{a} \frac{V_{d c}}{2} \\
& i_{i n v}=\frac{2 I_{d c}}{\sqrt{3} m_{a} \cos \phi}
\end{aligned}
$$

Reference sinusoidal signal for PWM generator is obtained with the help of PI controller for the inverter gating pulses. Actual voltage output at the inverter terminals and the reference voltage are compared in the PI controller and the error signal decides the value of PWM inverter gating signal and the value of modulation index to obtain desired power output.

PI controller parameters $K_{p}$ and $K_{i}$ are designed to fulfill following criteria-

- $\quad$ DC link voltage overshoot should remain within $10 \%$.

- $\quad$ DC link voltage should reach inside $2 \%$ band in less than 2 sec.

Based on above $K_{p}$ and $K_{i}$ are calculated using Eq. (26) and (27) -

$$
K_{i}=\omega_{n}^{2}=\left(\frac{4}{\zeta t_{s}}\right)^{2}
$$

$$
K_{p}=2 \zeta \omega_{n}
$$

Size of inverter is decided by considering following points -

- $\quad$ Maximum active power at given power factor to be fed to the grid/load, it increases with dc link voltage.

- Inverter functions as reactive power compensator, the reactive power required is another factor deciding the size of inverter.

- $\quad$ Grid/load voltage also influences the inverter design parameter.

As discussed in ${ }^{26}$, capacity of inverter to handle active and reactive power is governed by the rated current of power switches and dc link voltage. Therefore, rating of inverter is decided by the Eq. (28) given as-

$$
P_{i n v}=V_{d c} * I_{d c}
$$

For inverter switching, selection of switching frequency depends upon following facts [27]-

- $\quad$ At high switching frequency filtering of harmonic voltages become easier.

- $\quad$ Switching frequency should not lie in the audible range of $6 \mathrm{kHz}$ to $20 \mathrm{kHz}$.

- Sub harmonics can be avoided by using synchronous PWM method, as it requires modulation frequency to be an integer.

- If modulation frequency is chosen as an odd multiple of 3, most dominant harmonics in line to line voltage would be cancelled out.

In view of above mentioned features, $3 \mathrm{kHz}$ was chosen as inverter switching frequency. Also snubber parameters for rectifier and inverter is calculated using Eq. (29) and (30)- 


$$
\begin{aligned}
R_{s}>2 \frac{T_{s}}{C_{s}} & \\
& C_{s}<\frac{S}{1000(2 \pi f) V_{L L}{ }^{2}}
\end{aligned}
$$

(30)

Ripple filters are introduced to the WPGS at the inverter output stage as shown in Fig. 1, since IEEE519 standard recommended switching ripple filters to be designed to attenuate converter current harmonics for the power systems having non linear components. This reduces the risk of communication interference, system losses, resonance occurrence and malfunctioning of power electronic equipments.

\section{Battery Energy Storage Unit}

WPGS of large size connected to grid do not present major problem with variation in generated power due to stiffness of the system. But for a small integrated or isolated WPGS, supplying various types of load without back up, the instants of low wind or interruption in power supply may lead to complete shutdown of the system. ${ }^{3}$ To avoid such circumstances, it is advised to include back up of any type of energy storage out of pump water storage system, hydrogen storage, flywheel or battery energy storage. Battery energy storage unit (BESU) is ranked at the top among all, for small size IWPGS application, for high efficiency, high speed response, low maintenance and small space requirement [3]. The BESU overcomes the problem of undesirable power fluctuations and provides peak load capacity. It stores excess power during increased wind power generation and provides power to the load during low winds. In IWPGS with battery backup, the BESU is installed across the DC link capacitor of power electronic interface as shown in Fig. 6.

Battery backup is evaluated using formulae-

$$
\frac{E_{B E S U}}{P_{i}}=T_{B E S U}
$$

The DC link capacitance is evaluated using formulae-

$$
E_{B E S U}=\frac{1}{2} C_{d c} V_{d c}{ }^{2}
$$

Where $E_{B E S U}, T_{B E S U}$ and $P_{i}$ are total energy in BESU in Joules, time constant in sec and inverter power in Watts respectively.

The DC link capacitor is used to reduce current ripples bidirectional between inverter and BESU. Therefore the value of DC link capacitor should be kept small and the voltage at BESU is designed to vary from $95 \%$ to $0.95 \times 50 \%$ of DC link voltage [8].

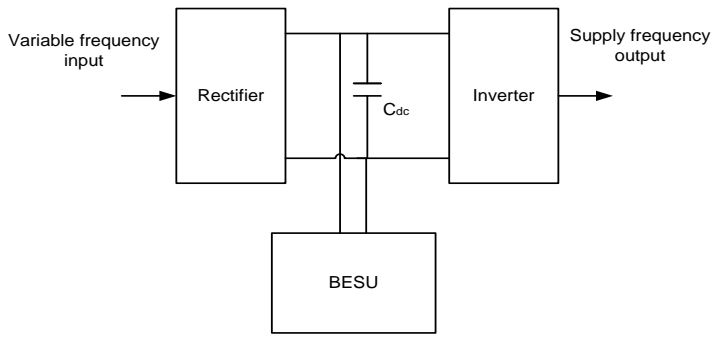

Fig.6 Schematic diagram of RII with BESU

\section{Performance Of Isolated Wind Power Generation System}

To investigate the performance of IWPGS a simulation model is prepared and detailed simulation studies is carried out, the results are analyzed for steady state and during transients. Fig. 7 shows the results for simulated wind speed waveform for wind speed variation from $8 \mathrm{~m} / \mathrm{s}$ to $14 \mathrm{~m} / \mathrm{s}$ range; optimized wind speed input is given to the variable speed wind turbine. Fig. 8 shows the simulated waveforms for tip speed ratio $(\lambda)$, power coefficient $\left(\mathrm{C}_{\mathrm{p}}\right)$, mechanical power $\left(\mathrm{P}_{\mathrm{m}}\right)$ and mechanical torque $\left(\mathrm{T}_{\mathrm{m}}\right)$ for given wind speed range, for $(\mathrm{a})$ constant pitch angle and (b) with pitch angle control. As shown in Fig. 9(a) for variable wind speed when pitch angle is kept constant at $15^{\circ}$, resulting waveforms show that the mechanical power and torque available at shaft are varying with time, following the wind speed variation. While with pitch angle control of blades through Pcontroller response is shown in Fig. 9(b), here wind speed is taken as reference signal. The proportionality 
control is responsible for rapid change in the control output and integral of error signal leads control towards zero under steady state.

Under normal operating conditions, pitch angle is controlled through P-controller only, reason being that the system is never in steady state due to varying nature of wind. The advantage of integral controller to approach zero steady state error is insignificant in such case and so, can be ignored. It is observed from the waveforms shown; that the mechanical quantities like mechanical power and mechanical torque are within optimum limits with varying wind. Therefore the excessive stress on wind turbine structure is avoided with pitch angle control under extreme wind conditions providing optimum power output, thus the stress on the aerodynamic converter is also reduced making power transfer smooth. Simulation response of aerodynamic converter without and with pitch angle control of wind turbine is shown in Fig. 10. The electrical torque $\left(T_{e}\right)$ available at PMSG output varies sinusoidally with time and seen optimized with pitch angle control as compared to that with constant pitch.

Generator voltage $\left(\mathrm{v}_{\mathrm{g}}\right)$ - generator current $\left(\mathrm{i}_{\mathrm{g}}\right)$, DC link voltage $\left(\mathrm{V}_{\mathrm{dc}}\right)$, inverter voltage $\left(\mathrm{v}_{\text {inv }}\right)$, output voltage $\left(\mathrm{v}_{\mathrm{L}}\right)$ - load current $\left(\mathrm{i}_{\mathrm{L}}\right)$ and output voltage $\left(\mathrm{v}_{\mathrm{S}}\right)$ - output current $\left(\mathrm{i}_{\mathrm{s}}\right)$ waveforms shown in Fig. 11, for IWPGS supplying a set of loads mentioned above during peak hours, at steady state reveal that the source voltage and current contain harmonics, that need be conditioned before being used by consumer for better efficiency and low power losses. Active power (p) and reactive power (q) waveforms for IWPGS during peak load in steady state are shown in Fig. 12. Active power delivered by source is $11.97 \mathrm{~kW}$, while the reactive power consumption is observed $6.077 \mathrm{kVAr}$. Almost all consumer loads are inductive in nature raising the problem of lagging power factor (0.8917) and therefore reactive power consumption. The THD in output voltage and current are observed as $8.61 \%$ and $13.18 \%$ respectively. Hence it becomes compulsion for the IWPGS to be harmonic free with unity power factor.

Fig. 13 depicts transient state parameters for IWPGS during peak load and after start up of induction motor, wherein it is observed that the dynamic loads like induction motor take current almost 4.6 times higher than full load current during starting because of high starting torque requirement. It is observed that, for the load current it takes around $0.3 \mathrm{sec}$. to settle down to its final value, and therefore the output current also settles taking the same time. Fig. 14 shows active power (p) and reactive power (q) waveforms for IWPGS for above conditions, variation in power output shows unstable performance during startup of three phase induction motor. Therefore, it is suggested to improve the power quality of the IWPGS in such a way so that its performance becomes stable under different operating conditions.

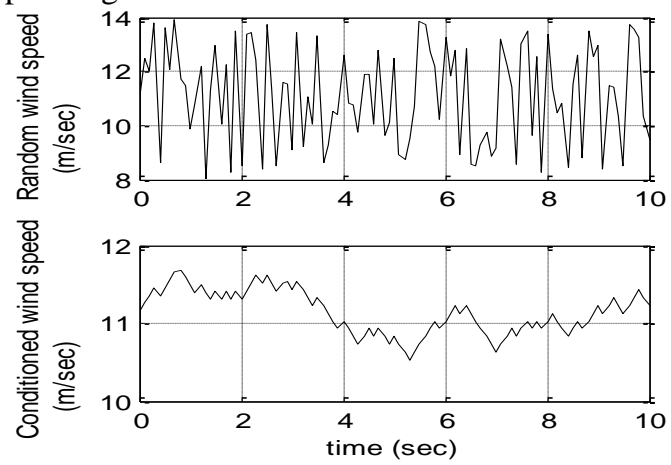

Fig.7 Simulated waveform of (a) random wind speed (b) conditioned wind speed 

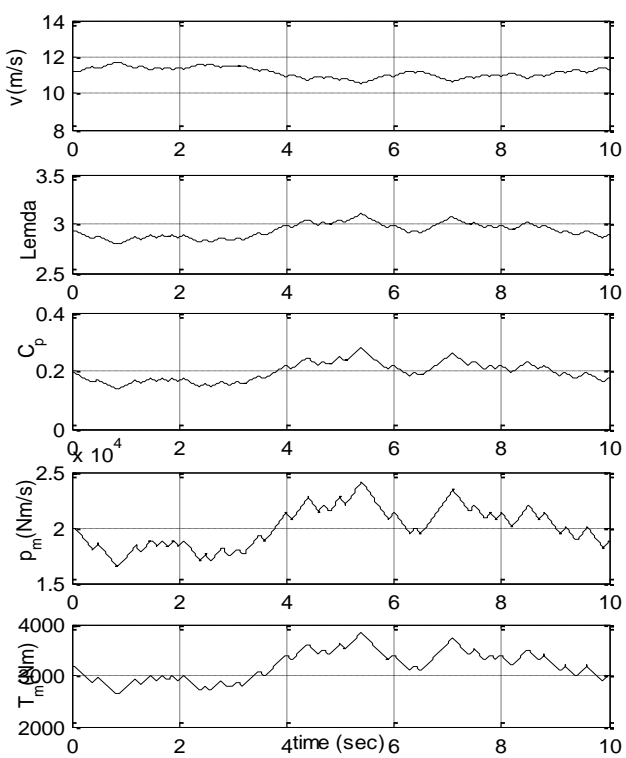

Fig.8 shows the simulated waveforms for tip speed ratio $(\lambda)$, power coefficient $\left(C_{p}\right)$, mechanical power $\left(P_{m}\right)$ and mechanical torque $\left(T_{m}\right)$ for given wind speed range

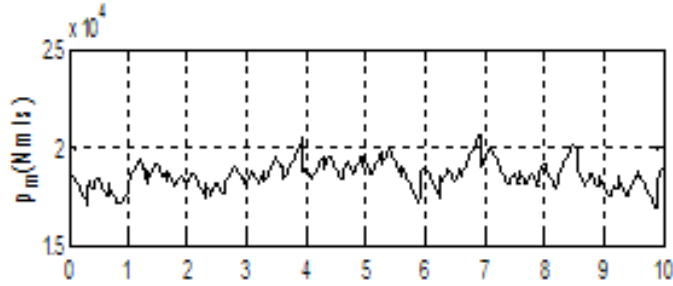

(a)

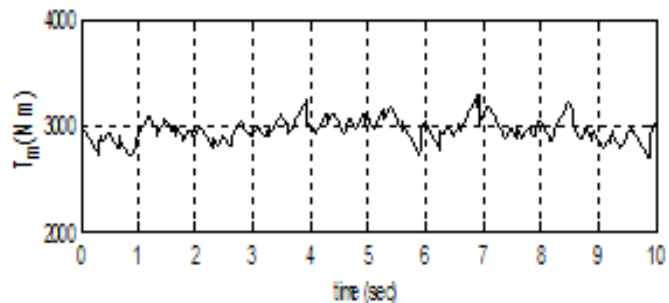

(b)

Fig. 9 Simulation response of wind turbine with (a) constant pitch, (b) pitch angle control

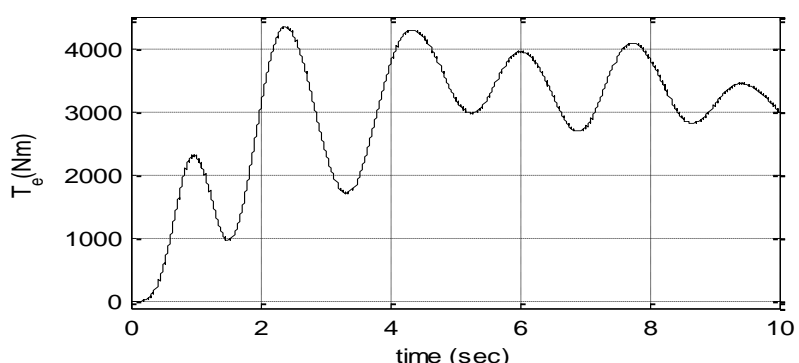

(a)

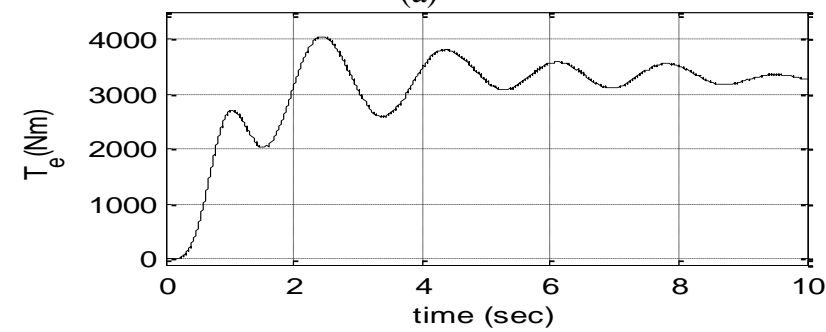


(b)

Fig.10 Simulation response of aerodynamic converter with (a) constant pitch, (b) pitch angle control
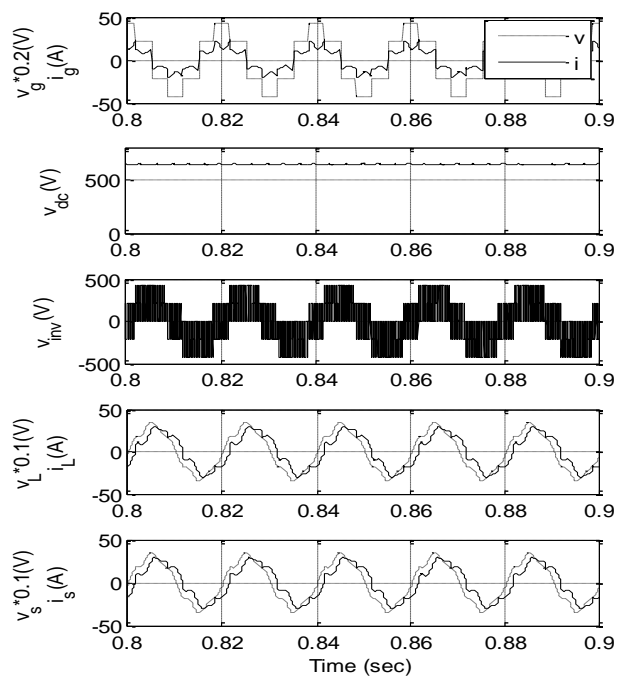

Fig.11 Steady state response for IWPGS during peak load

[Output voltage THD is $8.61 \%$, output current THD is $13.18 \%$, power factor is 0.8917 ]
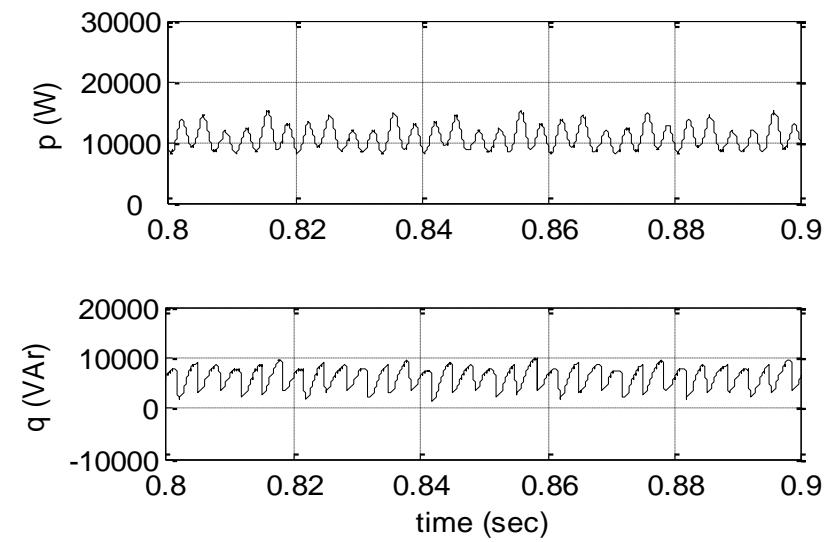

Fig.12 Active power (p) and reactive power (q) waveforms for IWPGS in steady state 

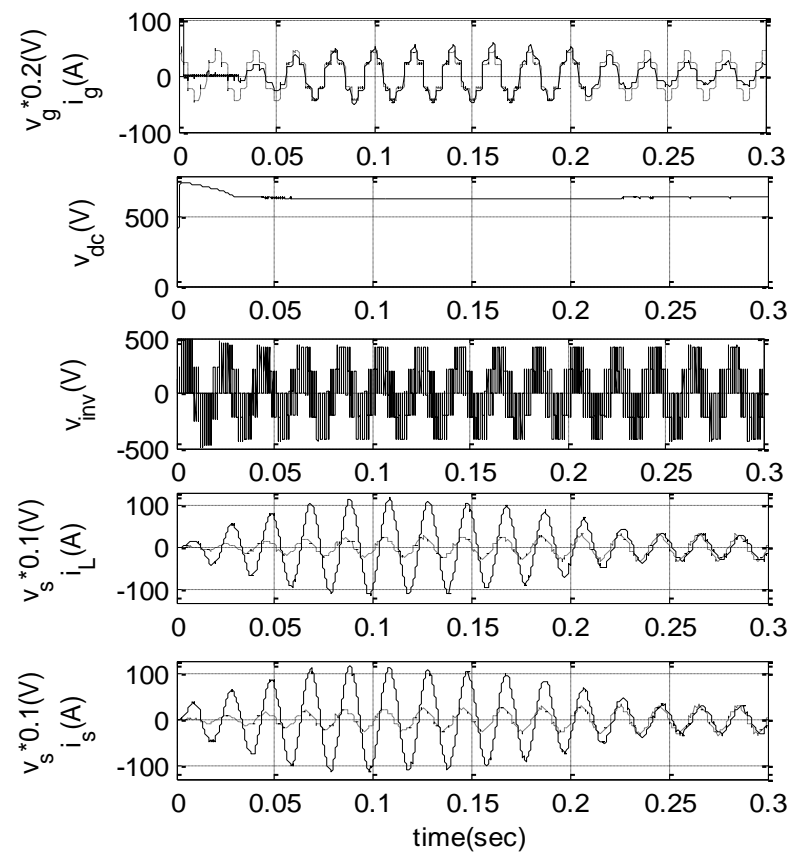

Fig.13 Transient response of IWPGS, after start up of induction motor at $0.0 \mathrm{sec}$
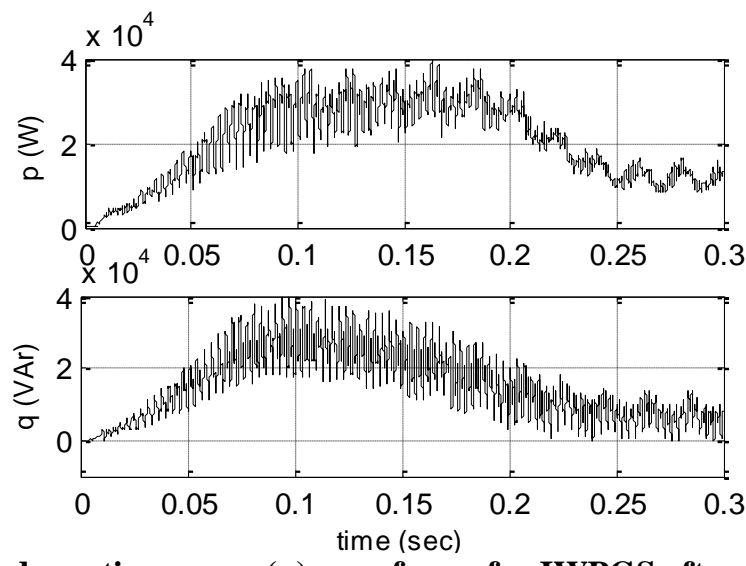

Fig. 14 Active power (p) and reactive power (q) waveforms for IWPGS after start up of induction motor

\section{A. Performance of IWPGS without BESU}

To investigate the performance of IWPGS with BESU a simulation model is prepared and study of system is done for low wind or no supply conditions. Fig. 15 give a picture of various voltages and currents for phase R, during no wind, which shows the total shut down occurrence during such events. Fig.16 represents instantaneous active power (p) and reactive power (q) at IWPGS output for no wind condition from 0.6 to 0.8 sec, it is observed that the performance of IWPGS without BESU may lead to discontinuous output power resulting in poor reliability. As observed from simulation results, it is clear that an IWPGS without backup would no longer be performing well in moderate climate condition; therefore it is advisable to install a BESU along with IWPGS to get consistent power supply. 


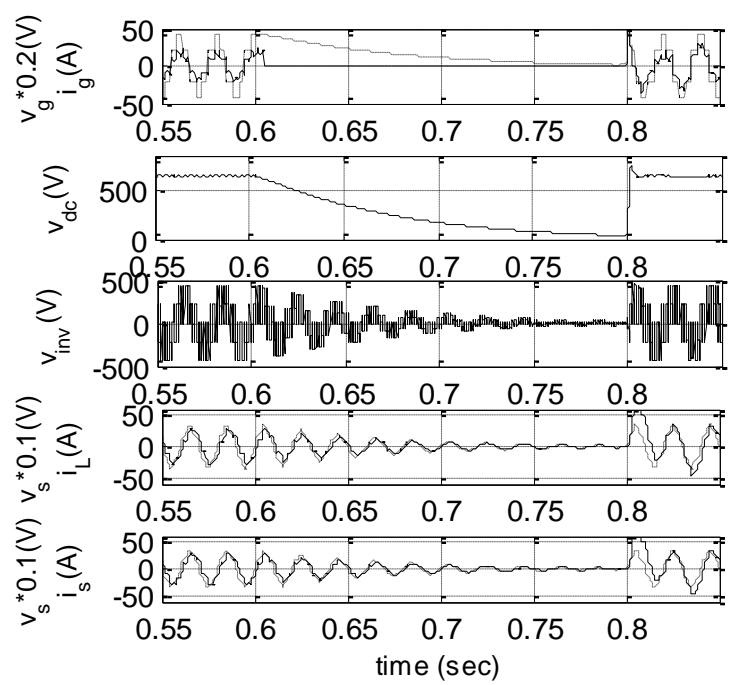

Fig.15 Transient response for IWPGS without BESU during no wind

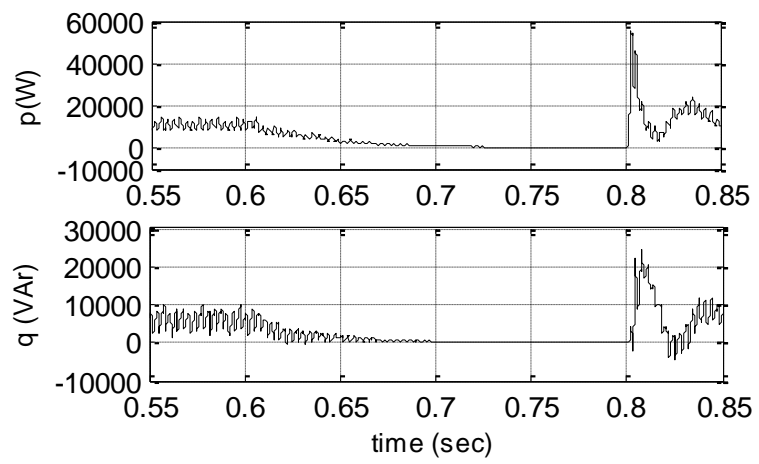

Fig.16 Active power (p) and reactive power (q) waveforms for IWPGS during no wind

\section{B. Performance of IWPGS with BESU}

To analyze the performance of BESU, BESU is installed across the DC link capacitor of RII of IWPGS. Various voltage and current waveforms for IWPGS having BESU during no wind condition from 0.6 to $0.8 \mathrm{sec}$ are shown in Fig. 17; it is observed that the consistent supply is available with BESU connected to IWPGS during no wind. However, presence of harmonics and reactive power required in the system is still a problem. Fig.18 represents instantaneous active power (p) and reactive power (q) at IWPGS with BESU, during no wind. It is observed that the reactive power is being supplied back to the system with BESU inserted in the system; however the transients are still contaminating the system output power.

Now output current lags output voltage with a power factor of 0.9284 , output voltage THD is $7.34 \%$ and output current THD is observed $9.69 \%$ during no wind. The DC link voltage across the BESU drops by $5.28 \%$ during no wind, active power supply from the source is also observed to be reduced from $11596.14 \mathrm{~W}$ to 10027.22 W in this duration. However, consistency of the supply makes the system performance reliable even under no wind condition. To reduce harmonics in output voltage and output current and to improve the power factor, active power filter is introduced. 


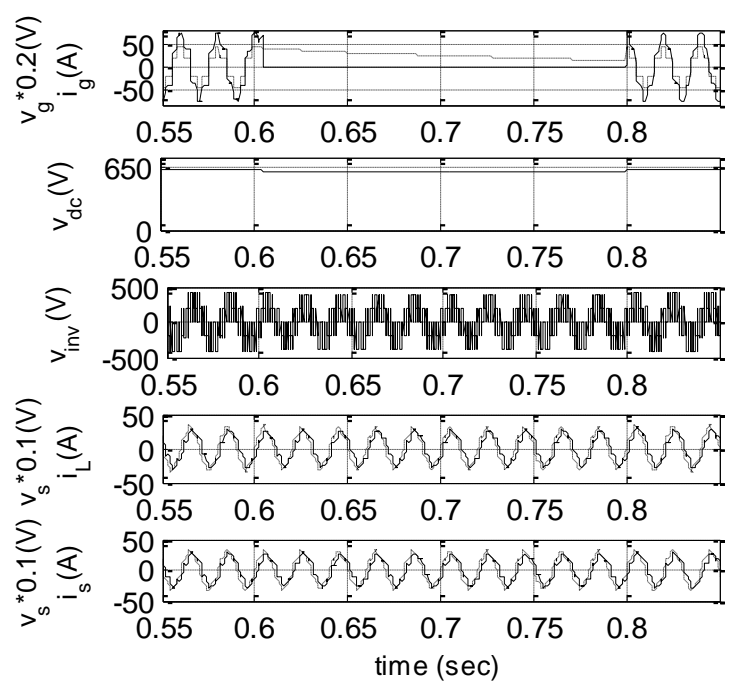

Fig.17 Transient response for IWPGS with BESU during no wind

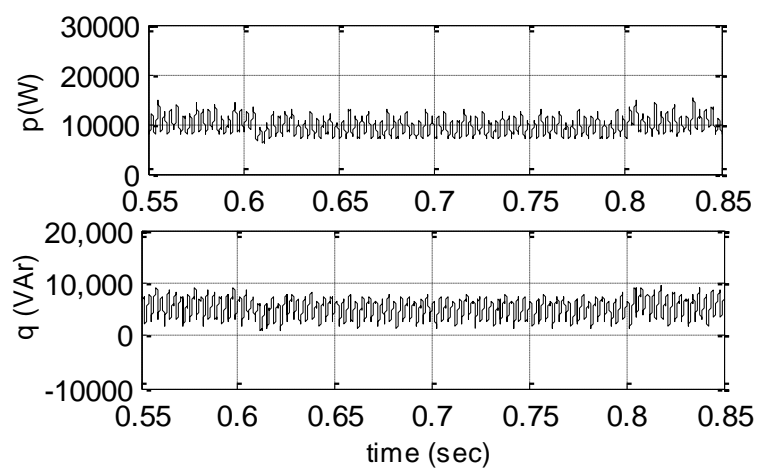

Fig.18 Active Power (P) and Reactive Power (Q) Waveforms for IWPGS with BESU during No Wind

\section{Iwpgs With Besu And Active Power Filter}

Presence of harmonics in system voltage and load current waveforms may result in poor power factor, heat losses and interruptions, and malfunction of equipments connected to the system. For the serious concern of service providers and utilities towards the power quality, IEC 61400-2 and IEEE 519 standards have specified regulations for voltage and current harmonic distortion limits [13]. In IWPGS using VSWT, the reactive power and harmonic distortions are present at the generator output, that too varying with varying wind conditions. Purpose of RII is to maintain the output voltage sinusoidal, but it does not comply with the standards to keep total harmonic distortion in system voltage and current within specified limits. When IWPGS supplies electrical power to non-linear load, the system performance shows more severe harmonic and reactive power conditions.

In early days passive filters were a viable solution to the IWPGS for harmonic reduction; for the reason of their low cost and high reliability. However, the limitation of passive filter of fixed compensation and resonance with other system parameters implore for advanced solution. Shunt active power filter emerged as such solution to compensate harmonics [28, 29]. However, a complete solution to both voltage and current harmonics is still suggested to be done with the implementation of hybrid active power filter, a combination of both passive filter and shunt active power filter.

\section{A. Performance of IWPGS with BESU and Active Power Filter}

When active power filter is inserted in the IWPGS delivering power to different types of loads as shown in Fig. 8, it is expected that the lower order harmonics are compensated by tuned passive filter, while higher order harmonic currents and reactive power are taken care of by shunt active power filter. Fig. 19 to Fig. 24 illustrates the performance of the IWPGS with APF for steady state condition and for transient condition as well.

Fig. 19 demonstrates generator voltage $\left(\mathrm{v}_{\mathrm{g}}\right)$ - generator current $\left(\mathrm{i}_{\mathrm{g}}\right)$, DC link voltage $\left(\mathrm{v}_{\mathrm{dc}}\right)$, inverter voltage output $\left(\mathrm{v}_{\text {inv }}\right)$, output voltage $\left(\mathrm{v}_{\mathrm{s}}\right)$ - load current $\left(\mathrm{i}_{\mathrm{L}}\right)$, output voltage $\left(\mathrm{v}_{\mathrm{s}}\right)$ - output current $\left(\mathrm{i}_{\mathrm{s}}\right)$, active power filter DC link capacitor voltage $\left(\mathrm{v}_{\mathrm{dcf}, \mathrm{f}}\right)$ and active power filter compensating current $\left(\mathrm{I}_{\mathrm{f}}\right)$ waveforms for IWPGS with APF, for condition of steady state. It is observed that the DC link voltage across both PE interface 
capacitance and that across the active power filter capacitance follow the reference value. It is observed that output voltage THD $(2.78 \%)$ and current THD $(4.06 \%)$ reduced to well below the limits imposed by IEEE 519 or IEC 51400-21 standards. Also, power factor has improved from 0.8917 near unity i.e. 0.9999 with the inclusion of APF. The rating of active power filter is $42.67 \%$ of that of supply with APF connected to IWPGS. Instantaneous active power (p) and reactive power (q) at IWPGS output at steady state are shown in Fig. 20. The reactive power consumption from the system reduces from $6077.27 \mathrm{kVAr}$ to $209.67 \mathrm{kVAr}$, the remaining being absorbed by passive filter components. Fig. 21 shows various output voltages and currents during transient occurrence (switching-in of all the loads), it is observed that, active power filter is switched in at $0.05 \mathrm{sec}$ and the DC link voltage of APF settles to final voltage within $0.2 \mathrm{sec}$, making the system stable. Fig. 22 shows the active and reactive power waveforms during transients, with the inclusion of active power filter the active and reactive power also seen to be settled to compensate values within $0.2 \mathrm{sec}$.

Fig. 23 illustrates various voltage and current waveforms for IWPGS having BESU with APF, for condition of no wind. From simulation results, the DC link voltage is seen to be less fluctuating (less than 1\%) compared to earlier case of no wind condition. Fig. 24 represents instantaneous active power (p) and reactive power (q) at IWPGS output for above mentioned conditions. Reactive power consumption reduced to 124.62 $\mathrm{kVAr}$ and active power delivered is $10199.79 \mathrm{~W}$ during no wind condition, as observed from simulation results.

Different components for IWPGS before and after compensation through active power filter are enlisted in Table - II. It may be concluded here that the lower order harmonics i.e. fifth and seventh order harmonics are supplied by passive filter to the load, while higher order harmonics and reactive power losses are injected by active power filter.

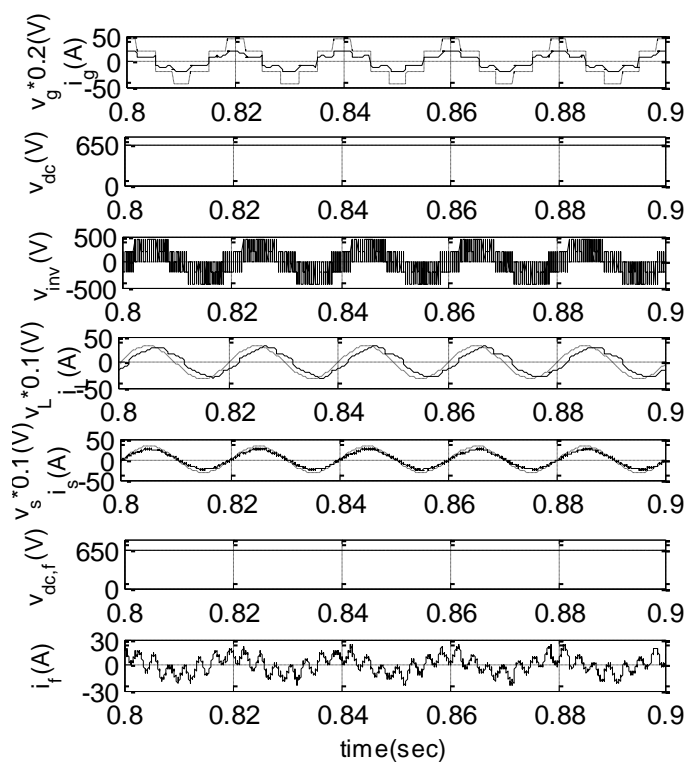

Fig.19 Steady state response of IWPGS with APF

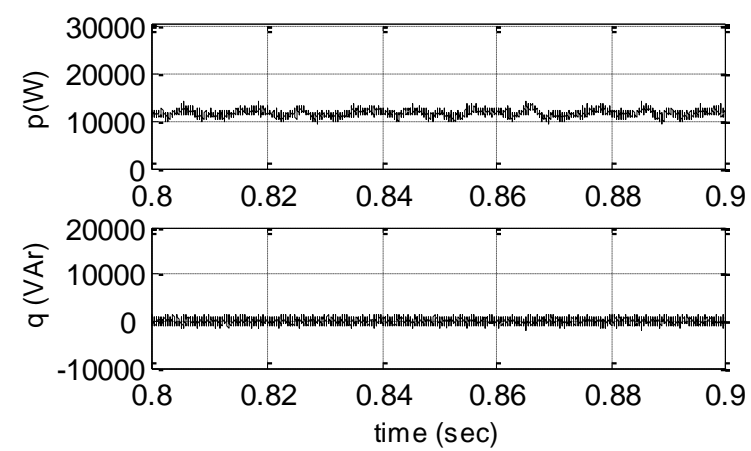

Fig.20 Active power (p) and reactive power (q) waveforms for IWPGS with APF, at steady state 

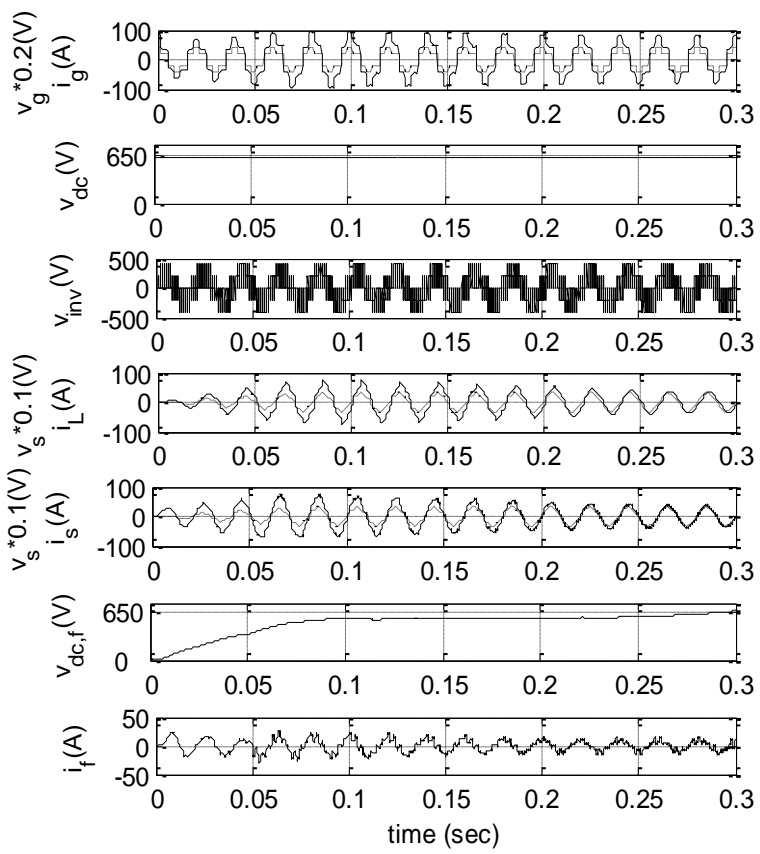

Fig.21 Switch in response of IWPGS with APF, APF switched in at 0.05 sec.
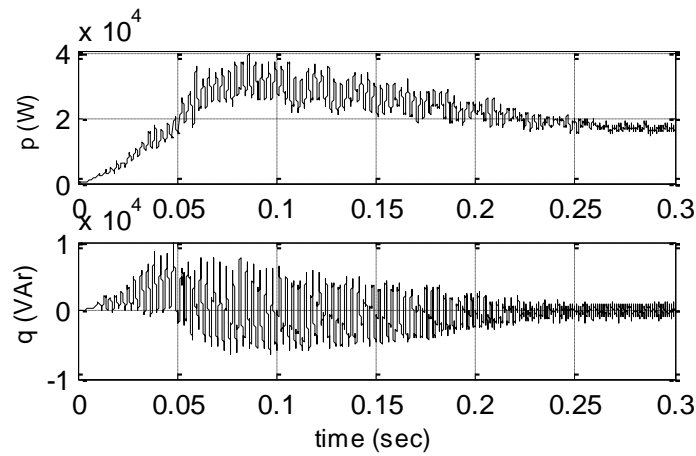

Fig.22 Active power (p) and reactive power (q) waveforms for IWPGS with APF switched on at 0.05 sec., after start-up of induction motor at 0.0 sec.

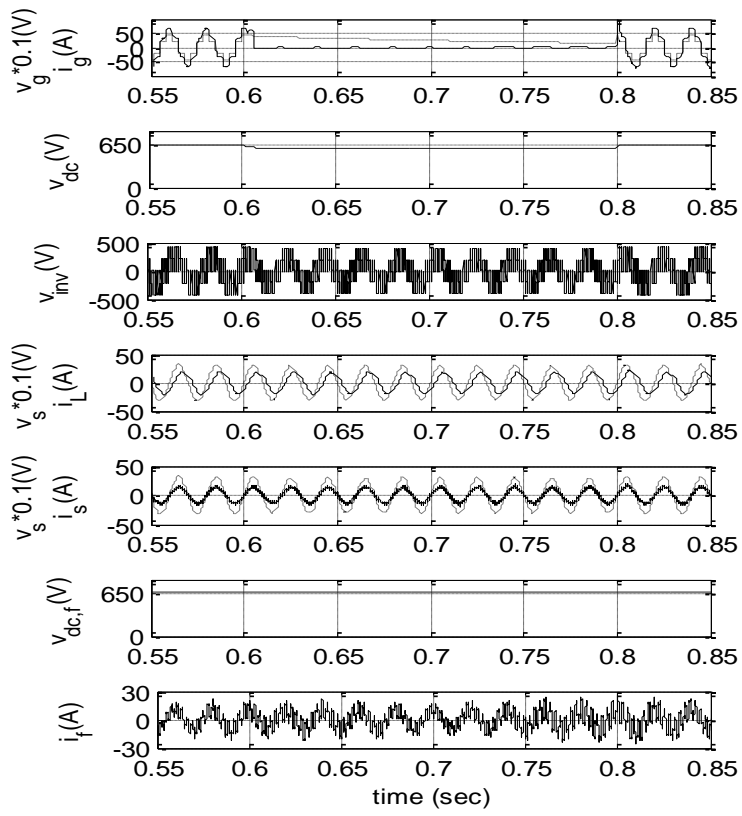

Fig.23 Transient response for IWPGS with BESU and APF during no wind condition 


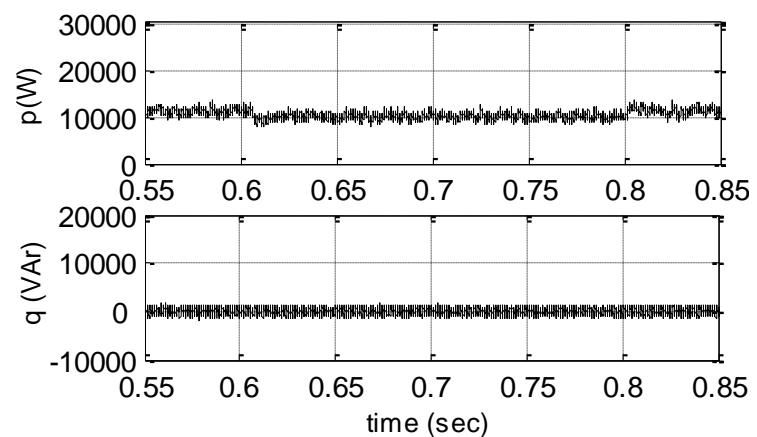

Fig.24 Active power (p) and reactive power (q) waveforms for IWPGS with BESU and APF during no wind condition

Table II Different components before and after compensation.

\begin{tabular}{|c|c|c|}
\hline Component & $\begin{array}{l}\text { Before } \\
\text { compensation }\end{array}$ & $\begin{array}{l}\text { After compensation } \\
\text { With APF }\end{array}$ \\
\hline$\% \mathrm{THD}$ in $\mathrm{v}_{\mathrm{s}}$ & $8.61 \%$ & $2.78 \%$ \\
\hline$\% \mathrm{THD}$ in $\mathrm{i}_{\mathrm{s}}$ & $13.18 \%$ & $4.06 \%$ \\
\hline Active power (W) & 11978.96 & 12011.60 \\
\hline Reactive power (VAr) & 6077.27 & 209.67 \\
\hline Apparent power (VA) & 13432.38 & 12014.00 \\
\hline APF current (A) & - & 7.459 \\
\hline APF rating & - & $42.67 \%$ of load power \\
\hline Power factor & 0.8917 & 0.9999 \\
\hline
\end{tabular}

\section{Conclusions}

The increased penetration of wind power into power generation system search for a solution that should be viable technically as well as economically. IWPGS may emerge as such an option to reach the consumer, without burdening the power generation system in terms of load. A scaled down model of IWPGS is simulated in matlab, keeping in mind for remote area applications, where transmission network is not feasible. The BESU is suggested to improve the system stability under low wind or no supply condition. The IWPGS is observed to show good dynamic performance with BESU. Various simulation results are obtained under steady state and during transients for peak load conditions. Wind energy sources are equivalent to current fed type load, as they have lagging power factor characteristics. Therefore, a hybrid of passive filter and shunt active power filter is suggested to improve the power quality of IWPGS. The proposed active power filter has been observed to be capable of minimizing the source current harmonics without requiring fine tuning of components, keeping the power factor near unity over a wide variation of load. The transients in the source current due to switching action reduce faster because of the presence of tuned passive filter. It may be concluded that the use of power electronic converters as interface or as load does not have any alternative. However, active power filter may be used to improve the power quality of WPGS, so that optimum power transfer is possible with minimum distortion in voltage and current.

\section{Appendix}

Various parameters selected for simulation studies for a $10 \mathrm{kVA}$ system are as follows-

$\mathrm{V}_{\mathrm{s}}=3-\Phi, 400 \mathrm{~V}, \mathrm{f}=50 \mathrm{~Hz}, \mathrm{RII}-\mathrm{C}_{\mathrm{dc}}=2200 \mu \mathrm{F}, \mathrm{R}_{\mathrm{s}}=100 \Omega, \mathrm{C}_{\mathrm{s}}=0.1 \mu \mathrm{F}, \mathrm{K}_{\mathrm{p}}=0.02, \mathrm{~K}_{\mathrm{i}}=20$

BESU - $\mathrm{R}_{\mathrm{b}}=10 \mathrm{k} \Omega, \mathrm{C}_{\mathrm{b}}=25.5 \mathrm{mF}, \mathrm{R}_{\mathrm{se}}=0.5 \Omega, \mathrm{V}_{\mathrm{b}}=600 \mathrm{~V}$

APF $-\mathrm{R}_{\mathrm{f}}=0.1 \Omega, \mathrm{L}_{\mathrm{f}}=2 \mathrm{mH}, \mathrm{V}_{\mathrm{dc}}=650 \mathrm{~V}, \mathrm{C}_{\mathrm{dc}}=2200 \mu \mathrm{F}, \mathrm{K}_{\mathrm{p}}=0.09, \mathrm{~K}_{\mathrm{i}}=0.9$

Tuned harmonic filters $-\mathrm{R}_{5}=0.1 \Omega, \mathrm{L}_{5}=4 \mathrm{mH}, \mathrm{C}_{5}=100 \mu \mathrm{F}, \mathrm{R}_{7}=0.1 \Omega, \mathrm{L}_{7}=2 \mathrm{mH}, \mathrm{C}_{7}=100 \mu \mathrm{F}$

\section{References}

[1]. M.E. Haque, M. Negnevitsky, and K.M. Muttaqi, A novel control strategy for a variable-speed wind turbine with a permanentmagnet synchronous generator, IEEE Transactions on Industry Applications, 46(1), 2010, 331-338.

[2]. W. Kramer, S. Chakraborty, B. Kroposki, and H. Thomas, Advanced power electronic interfaces for distributed energy systems Part 1: Systems and topologies, Technical Report NREL/TP-581-42672, March 2008.

[3]. B. Singh and G.K. Kasal G. K, Solid state voltage and frequency controller for a standalone wind power generating system, IEEE Transactions on Power Electronics, 23(3), 2008, 1170-1177.

[4]. J.A. Baroudi, V. Dinavahi and A. M. Knight, A review of power converter topologies for wind generators, Renewable Energy, 32(14), 2007, 2369-2385.

[5]. J.M. Carrasco, L.G. Franquelo, J.T. Bialasiewicz, E. Galvan, R.C.P. Guisado, Ma.A.M. Prats, J.J.I. Leon, and N. MorenoAlfonso, Power-electronic systems for the grid integration of renewable energy sources: a survey, IEEE Transactions on Industrial Electronics, 53(4), 2006, 1002-1016. 
[6]. H. Geng and G. Yang, Output power control for variable-speed variable-pitch wind generation systems, IEEE Transactions on Energy Conversion, 25(2), 2010, 494-503.

[7]. F. Iov and F. Blaabjerg, Power electronics and control for wind power systems, Proc. of IEEE Conf. on Power Electronics and Machines in Wind Applications, PEMWA, 2009, 1-16.

[8]. P. Mercier, R. Cherkaoui, and A. Oudalov, Optimizing a battery energy storage system for frequency control application in an isolated power system, IEEE Transactions on Power Systems, 24(3), 2009, 1469-1477.

[9]. X.Y. Wang, D.M. Vilathgamuwa and S.S. Choi, Determination of battery storage capacity in energy buffer for wind farm, IEEE Transactions on Energy Conversion, 23(3), 2008, 868-878.

[10]. S. Li and L. Xu, PWM converter control for grid integration of wind turbines with enhanced power quality, Proc. of 34th Annual Conf. of IEEE Industrial Electronics, IECON 2008, 2218-2224.

[11]. E. Muljadi and H.E. McKenna, Power quality issues in a hybrid power system, IEEE Transactions on Industrial Applications, 38(3), 2002, 803-809.

[12]. T.M.H. Nicky, K. Tan, and S. Islam, Mitigation of harmonics in wind turbine driven variable speed permanent magnet synchronous generators, Proc. of Power Engineering Conf. IPEC 2005, 2005, 1-6.

[13]. Photovoltaics, D. G., \& E. Storage, IEEE Standards Coordinating Committee, IEEE application guide for IEEE Standards 1547.2-2008, IEEE Standard for Interconnecting Distributed Resources with Electric Power Systems 21, 15 April 2009.

[14]. B.R. Lin, B.R. Yang, and H.R. Tsai, Analysis and operation of hybrid active filter for harmonic elimination, Electric Power Systems Research, 62(3), 2002, 191-200.

[15]. J. Tsai and K. Tan, HAPF harmonic mitigation technique for PMSG wind energy conversion system, Proc, of Australasian Universities Power Engineering Conf., AUPEC 2007, 1-6.

[16]. T. Petru and T. Thiringer, Modeling of wind turbines for power system studies, IEEE Transactions on Power Systems, 17(4), 2002, 1132-1139.

[17]. E.J.R. Sambatra, G. Barakat, and B. Dakyo, Analytical modeling and experimental validation of the dynamic behavior of permanent magnet synchronous machine based wind energy converter, Proc. of European Conf. on Power Electronics and Applications, EPE 2005, Dresden, 1-10.

[18]. J.G. Slootweg, S.W.H. de Haan, H. Polinder, and W.L. Kling, General model for representing variable speed wind turbines in power system dynamic simulations, IEEE Transactions on Power Systems, 18(1), 2003, 144-151.

[19]. X. Wu, W. Wang, H. Dai, and Y. Chen, Application of models of the wind energy conversion system to wind power dynamic analysis, Proc. of IEEE International Conference on Power System Technology, 1998, 2, 1406-1411.

[20]. F.D. Bianchi, H. De Battista, and R.J. Mantz, Wind turbine control systems- principles, modeling and gain scheduling design ( Springer links, April 2006).

[21]. S.M. Muyeen, R. Takahashi, T. Murata, and J. Tamura, A variable speed wind turbine control strategy to meet wind farm grid code requirements, IEEE Transactions on Power Systems, 25(1), 2010, 331-340.

[22]. L.Y. Pao and K.E. Johnson, A tutorial on the dynamics and control of wind turbines and wind farms, American Control Conf., St. Louis, MO, USA, 2009, 2076-2089.

[23]. N.A. Orlando, M. Liserre, V.G. Monopoli, R.A. Mastromauro, and A. Dell'Aquila, Comparison of power converter topologies for permanent magnet small wind turbine system, Proc. of IEEE International Symposium on Industrial Electronics, ISIE 2008, 2008, 2359-2364.

[24]. Y. Amirat, M.E.H. Benbouzid, B. Bensaker, and R. Wamkeue, Generators for wind energy conversion systems: state of the art and coming attractions, Journal of Electrical Systems, 3(1), 2007, 26-38.

[25]. M. Chinchilla, S. Arnaltes and J.C. Burgos, Control of permanent magnet generators applied to variable speed wind energy systems connected to the grid, IEEE Transactions on Energy Conversion, 21(1), 2006, 130-135.

[26]. L.S. Czarnecki, Instantaneous reactive power p-q theory and power properties of three-phase systems, IEEE Transactions on Power Delivery, 21(1), 2006, 362-367.

[27]. H. Sharma, S. Islam and C.V. Nayar, Power quality simulation of a variable speed wind generator connected to a weak grid, Proc. of 9th International Conf. on Harmonics and Quality of Power, 2000, 988-993.

[28]. F.S. dos Reis, J.A.V. Ale, F.D. Adegas, R. Tonkoski, S.Slan and K. Tan, Active shunt filter for harmonic mitigation in wind turbine generators, Proc. of 37th IEEE Power Electronics Specialists Conf., PESC`06, 2006, 1-6.

[29]. K.J.P. Macken, T.C. Green, and R.J.M. Belmans, Active filtering and load balancing with small wind energy systems, Proc.of 10th IEEE International Conf. on Harmonics and Quality of Power, 2002, 776-781. 